\title{
Comparative study of intra-articular pressure dynamics in joints with acute traumatic and chronic inflammatory effusions: potential implications for hypoxic-reperfusion injury
}

\author{
P Merry, R Williams, N Cox, J B King, D R Blake
}

\begin{abstract}
It has been proposed that the process of hypoxic-reperfusion injury contributes to the persistence of synovitis in the inflamed human joint. The generation of pathological, exercise induced, intra-articular pressure leading to occlusion of the synovial microcirculation is central to this mechanism. However, acute traumatic inflammatory joint effusions rarely result in chronic synovitis, suggesting that either the basic hypothesis is incorrect, or that joints with acute traumatic effusions show different intra-articular pressure dynamics.

In this study the intra-articular pressure was measured at rest and during isometric exercise in five patients with acute traumatic joint effusions and in nine patients with chronic inflammatory joint effusions. The generation of intra-articular pressure in the patients with acute traumatic effusions was significantly lower at rest (mean $2.0 v 19.6 \mathrm{~mm}$ $\mathrm{Hg}$ ) and during exercise (mean $13.7 v 222.5$ $\mathrm{mm} \mathrm{Hg}$ ) than in the patients with chronic effusions. This was due to reflex muscular inhibition around the joint, which inhibited the pathological generation of intra-articular pressure. This difference in the ability to generate intra-articular pressure might mitigate against hypoxic-reperfusion injury in joints with acute traumatic effusions, thereby explaining the paradoxical clinical observation that patients with acute traumatic inflammatory joint effusions rarely develop chronic synovitis.
\end{abstract}

The Inflammation Research Group, London Hospital Medical College, London E1 2AD, UK P Merry

D R Blake

Department of Rheumatology,

Royal Hampshire

County Hospital,

Romsey Road,

Winchester SO22 5DG

UK

$R$ Williams

N Cox

Department of

Orthopaedics,

The Royal London

Hospital, London

E1 2AD, UK

J B King

Correspondence to

Professor Blake.

Accepted for publication

19 December 1990 in occlusion of the synovial capillary bed and hypoxia. ${ }^{6}$ When exercise stops, the intraarticular pressure falls and reperfusion occurs. As a result, reactive oxygen species are generated by the uncoupling of a variety of intracellular redox systems, and oxidative damage occurs which affects lipids, IgG, hyaluronate, and to many of these biomolecules may initiate a chain of proinflammatory events, and we therefore conclude that hypoxic-reperfusion injury may contribute to the peculiar persistence of chronic inflammatory synovitis.

Intra-articular pressure is central to the mechanism of hypoxic-reperfusion injury to the joint. The dynamics of intra-articular pressure in acute traumatic effusions have never previously been investigated in humans. However, they are of interest because of the intriguing, and to us paradoxical, clinical observation that patients with acute traumatic inflammatory effusions rarely develop chronic synovitis.

In this study, we compared the pathophysiology of the generation of intra-articular pressure in patients with acute traumatic and chronic inflammatory joint effusions to assess whether a difference exists that might mitigate against hypoxic-reperfusion injury in joints with acute traumatic effusions, thereby explaining the paradox.

\section{Patients and methods}

PATIENTS

After approval by an ethical committee, two different groups of patients were studied: $(a)$ patients with chronic inflammatory knee effusions and $(b)$ patients with acute traumatic knee effusions.

Eight patients with chronic knee effusions and one patient with a chronic shoulder effusion were studied. The age range was $30-86$ years (mean 62 years) and the group consisted of three men and six women. There were four patients with rheumatoid arthritis, two with psoriatic arthritis, two with inflammatory osteoarthritis, and one with ankylosing spondylitis. All effusions had occurred for longer than two months (table 1).

Five patients (four men, one woman) with acute traumatic knee effusions were studied. The age range was $21-38$ years (mean 28 years). Three patients had lateral ligament strains, one a dislocated patella, and one an anterior cruciate ligament tear. All the effusions were detectable clinically and had been present for at least 24 hours but less than three days (table 2). albumin within the joint. ${ }^{389}$ Oxidative damage
METHODS

A miniature pressure transducer with a silicon diaphragm housed at the end of a $10 \mathrm{~cm}$ long stainless steel 14.5 gauge probe was used (Entran UK). The response of the transducer 
Table 1 Intra-articular pressure in patients with chronic inflammatory synovitis

\begin{tabular}{|c|c|c|c|c|c|c|}
\hline Patient no & Age & Sex* & Diagnosis* & $\begin{array}{l}\text { Duration of } \\
\text { effusion (months) }\end{array}$ & $\begin{array}{l}\text { Intra-articular } \\
\text { pressure at rest } \\
(\mathrm{mm} \mathrm{Hg})\end{array}$ & $\begin{array}{l}\text { Mean }(S D) \text { intra- } \\
\text { articular pressure } \\
\text { during exercise } \\
(m m H g)\end{array}$ \\
\hline $\begin{array}{l}1 \\
2 \\
3 \\
4 \\
5 \\
6 \\
7 \\
8 \\
9+\end{array}$ & $\begin{array}{l}30 \\
67 \\
67 \\
52 \\
62 \\
76 \\
68 \\
49 \\
86\end{array}$ & $\begin{array}{l}\mathbf{F} \\
\mathbf{M} \\
\mathbf{M} \\
\mathbf{M} \\
\mathbf{F} \\
\mathbf{M} \\
\mathbf{M} \\
\mathbf{F} \\
\mathbf{F}\end{array}$ & $\begin{array}{l}\text { RA } \\
\text { OA } \\
\text { PsA } \\
\text { AS } \\
\text { RA } \\
\text { RA } \\
\text { PsA } \\
\text { RA } \\
\text { OA }\end{array}$ & $\begin{array}{r}6 \\
12 \\
3 \\
2 \\
3 \\
4 \\
12 \\
12 \\
12\end{array}$ & $\begin{array}{r}15 \\
6 \\
23 \\
10 \\
12 \\
76 \\
5 \\
10 \\
15\end{array}$ & $\begin{array}{l}354(8 \cdot 5) \\
142 \cdot 5(4 \cdot 2) \\
252 \cdot 6(124 \cdot 8) \\
228 \cdot 5(63 \cdot 8) \\
102 \cdot 5(28 \cdot 5) \\
532 \cdot 5(39 \cdot 3) \\
50(1 \cdot 6) \\
117 \cdot 5(17 \cdot 1) \\
105 \cdot 25(26 \cdot 2)\end{array}$ \\
\hline
\end{tabular}

*Abbreyiations: $\mathrm{RA}=$ rheumatoid arthritis; $\mathrm{OA}=$ osteoarthritis; PsA=psoriatic arthritis; $\mathrm{AS}=$ ankylosing spondylitis. $\mathrm{F}=$ female; $\mathbf{M}=$ male.

†Patient 9 had a shoulder effusion; all other patients had knee effusions.

Table 2 Intra-articular pressure in patients with acute traumatic knee effusions

\begin{tabular}{lllllll}
\hline $\begin{array}{l}\text { Patient } \\
\text { no }\end{array}$ & Age & Sex & Diagnosis* & $\begin{array}{l}\text { Duration of } \\
\text { effusion (months) }\end{array}$ & $\begin{array}{l}\text { Intra-articular } \\
\text { pressure at rest } \\
(\text { mm Hg) }\end{array}$ & $\begin{array}{l}\text { Mean }(S D) \text { intra- } \\
\text { articular pressure } \\
\text { during exercise } \\
(\text { mm Hg) }\end{array}$ \\
\hline 10 & 38 & M & $\begin{array}{l}\text { Ligament strain } \\
\text { Dislocated patella }\end{array}$ & 1 & 0 & $17 \cdot 5(3)$ \\
11 & 21 & M & $\begin{array}{l}\text { Anterior cruciate } \\
\text { tear }\end{array}$ & 3 & 0 & $18 \cdot(4 \cdot 3)$ \\
13 & 28 & M & 3 & 6 & $21 \cdot 4(0 \cdot 9)$ \\
14 & 28 & M & $\begin{array}{l}\text { Ligament strain } \\
\text { Ligament strain }\end{array}$ & 2 & 0 & $-0 \cdot 6(3 \cdot 3)$ \\
\end{tabular}

*Abbreviations: $\mathrm{RA}=$ rheumatoid arthritis; $\mathrm{OA}=$ osteoarthritis; $\mathrm{PsA}=$ psoriatic arthritis; $\mathrm{AS}=$ ankylosing spondylitis. $\mathrm{F}=\mathrm{female}$; $\mathrm{M}=$ male.

was linear from -50 to $1500 \mathrm{~mm} \mathrm{Hg}$ between 0 and $60^{\circ} \mathrm{C}$. The probe was sterilised by immersion in $2 \%$ activated glutaraldehyde solution for two hours.

The subjects were rested in a recumbent position for 30 minutes before the measurements were taken. A 14 gauge PTFE cannula was introduced into the suprapatellar recess of the knee, from the medial approach, after subcutaneous infiltration of $2 \%$ lignocaine. Care was taken not to inject any anaesthetic into the joint cavity for two reasons: $(a)$ to avoid increasing the intra-articular effusion volume, hence raising the intra-articular pressure and $(b)$ to avoid any influence of the anaesthetic on the muscle tone of the quadriceps. On removal of the trochar, the pressure transducer was immediately introduced into the knee cavity via the cannula to measure the intra-articular pressure directly. The pressure probe was connected to a chart recorder (BBC Austria) to allow continuous measurement of the intraarticular pressure (fig 1). The intra-articular pressure was recorded at rest and during cycles of isometric quadriceps contraction and subsequent relaxation. A minimum of four cycles was performed per patient and a mean value for the intra-articular pressure during exercise was obtained. The subjects held their heads in a neutral position during testing to avoid the effect of tonic neck reflexes on the Hoffman reflex. ${ }^{10}$ The pressure probe was calibrated against a mercury manometer before and after all pressure measurements.

The intra-articular pressure was measured in one patient with a chronic inflammatory shoulder effusion. The joint cavity was cannulated from the anterior approach and exercise was by isometric shoulder abduction.

Statistical analysis was performed using the
Wilcoxon pairs test, as the data did not satisfy the required assumptions for analysis using parametric procedures.

\section{Results}

None of the patients experienced pain during quadriceps contraction. In all the patients with acute effusions a high degree of quadriceps

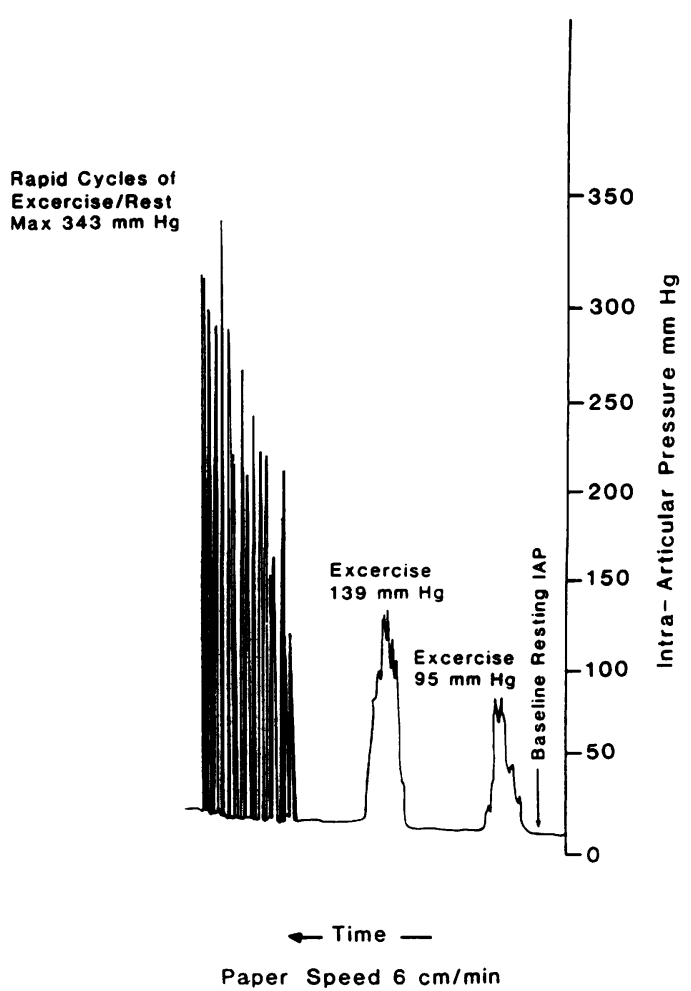

Figure 1 Typical example of recording of the intra-articular pressure from patient 4. 


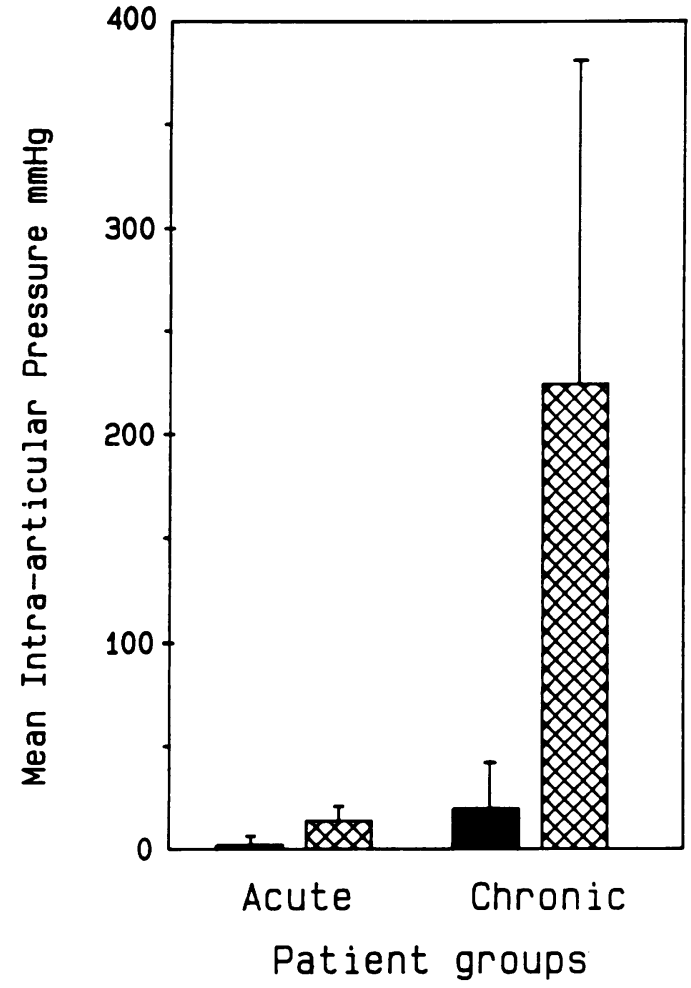

Figure 2 Bar chart illustrating the mean intra-articular pressure at rest and during isometric joint exercise, in patients with acute traumatic joint effusions and chronic inflammatory joint effusions. Solid blocks, rest; hatched blocks, exercise; bars, standard deviation.

inhibition was noted on contraction of the quadriceps. Quadriceps inhibition was not obvious in the patients with chronic effusions.

In the patients with chronic effusions, the mean (SD) intra-articular pressure at rest was $19.6(23.5) \mathrm{mm} \mathrm{Hg}$ and the mean intra-articular pressure during exercise was $222.5(158.6) \mathrm{mm}$ $\mathrm{Hg}$. In the patients with acute traumatic effusions, the mean (SD) intra-articular pressure at rest was $2 \cdot 0(2 \cdot 8) \mathrm{mm} \mathrm{Hg}$ and the mean intra-articular pressure during exercise was $13.7(8.6) \mathrm{mm} \mathrm{Hg}$. There is a clear difference in the generation of intra-articular pressure between the two groups. This is significant both at rest $(p<0.01)$ and during exercise $(p<0.001)$

\section{Discussion}

INTRA-ARTICULAR PRESSURE AT REST

In the patients with chronically inflamed joints the mean intra-articular pressure at rest was $19.6 \mathrm{~mm} \mathrm{Hg}$. This is consistent with the findings of other research groups. ${ }^{11-13}$ Patient 6 had a reproducible pressure of $76 \mathrm{~mm} \mathrm{Hg}$. Palmer and Myers ${ }^{12}$ recorded a similarly high resting intra-articular pressure of $80 \mathrm{~mm} \mathrm{Hg}$ in one patient with an inflammatory effusion.

Guyton $e a^{14}$ have reported that the capillary perfusion pressure in healthy tissues ranges between 10 and $20 \mathrm{~mm} \mathrm{Hg}$, thus an intraarticular pressure of $76 \mathrm{~mm} \mathrm{Hg}$ would be expected to compromise synovial perfusion and produce infarction of the synovium leading to gangrene. This did not occur in patient 6 , suggesting the presence of a protective mechanism to prevent total ischaemia of the synovium.
Levick ${ }^{15}$ suggests that the synovial vasculature is partially protected by the dense intervening bands of fibrils and collagen. A further explanation may be related to the fact that there is considerable variation in the capillary perfusion pressure between different types of tissue-for example, the mesentery in cats has a capillary perfusion pressure ranging between 30 and 40 $\mathrm{mm} \mathrm{Hg} .{ }^{16}$ The capillary perfusion pressure within normal human synovium is not yet known, but possibly it may be higher than that in the mesentery of cats, and in addition, it would be reasonable to expect a further increase in pressure in inflamed synovium ( $\mathrm{J}$ Levick, personal communication). Intra-articular pressure of $76 \mathrm{~mm} \mathrm{Hg}$ may therefore not necessarily compromise synovial perfusion.

In the group of patients with acute traumatic effusions the mean intra-articular pressure at rest was $2.0 \mathrm{~mm} \mathrm{Hg}$, significantly less than in patients with chronic joint effusions. This difference may be explained by lower quadriceps muscle tone in the group with traumatic effusions; these patients showed clinically greater quadriceps inhibition, an observation supported by other workers. ${ }^{17} 18$ In addition, the chronically inflamed joint capsule shows greater elasticity, ${ }^{13}$ suggesting an increased ability for the generation of intra-articular pressure.

INTRA-ARTICULAR PRESSURE DURING ISOMETRIC EXERCISE OF THE JOINT

During isometric quadriceps contraction of the joints in the patients with chronic effusions there was a large increase in the intra-articular pressure in all instances (mean $222.5 \mathrm{~mm} \mathrm{Hg}$ ). Several types of synovitis were studied and the increase in intra-articular pressure is clearly not specific to a particular disease. These findings are consistent with the findings of other workers. ${ }^{11} 1920$ The increase in the intraarticular pressure in most instances, was larger than the expected capillary perfusion pressure of the synovium and sometimes greater than the systolic blood pressure. The increase in the intra-articular pressure on contraction of the quadriceps was immediate and lasted throughout the contraction, whether this was five seconds or two minutes. On relaxation of the quadriceps contraction, the intra-articular pressure immediately fell to the value of the intra-articular pressure at rest.

One patient studied had a chronic inflammatory effusion affecting the shoulder joint. Isometric abduction of the shoulder joint produced a similar increase in the intra-articular pressure to that seen in the chronically inflamed knees, suggesting that the increase in the intraarticular pressure during exercise is not necessarily specific to one joint.

It is known that exercise of the normal human knee does not produce significant positive fluxes in the intra-articular pressure, ${ }^{19} 21$ emphasising the critical role of effusions in the generation of intra-articular pressure. However, during the isometric quadriceps contraction of knees with acute traumatic effusions, only a moderate rise in the intra-articular pressure was 
seen (mean $13.7 \mathrm{~mm} \mathrm{Hg}$ ) despite the presence of a significant clinically detectable effusion.

\section{EXERCISE INDUCED CHANGES IN THE INTRA-} ARTICULAR PRESSURE

The reason for the observed difference in the generation of intra-articular pressure between the patients with acute and chronic joint effusions may be explained by the large quadriceps inhibition seen in the patients with acute traumatic knee effusions. The patients with acute traumatic effusions had all had trauma to the knee within the previous three days and it is known that post-traumatic quadriceps inhibition is at a maximum during this time. ${ }^{17}$ No pain was experienced during attempted isometric quadriceps contraction in either group, which excluded the well described component of quadriceps inhibition secondary to pain. ${ }^{22-24}$

The production of quadriceps inhibition by knee joint effusions is well described ${ }^{19} 25$ and it is likely that the quadriceps inhibition seen in this study was a result of the joint effusion exerting its inhibitory effect via capsular mechanoreceptors, ${ }^{26} 27$ resulting in inhibition of the Hoffman reflex. ${ }^{28}$ Jones et al ${ }^{18}$ concluded that in chronic synovitis the effusion within the knee joint does not provoke significant quadriceps inhibition, in contrast with the marked inhibition seen in joints with acute traumatic effusions. ${ }^{17}$ This study supports this observation and also exposes the pathophysiological consequence by showing that patients with acute traumatic knee effusions do not generate high intra-articular pressures during exercise of the joint.

There are several other possible explanations for the difference between the two groups. Acute effusion into a previously normal joint is known to generate a lower intra-articular pressure, volume for volume, than effusion into a chronically inflamed joint, owing to the higher capsular elasticity in the chronically inflamed joint. ${ }^{13}$ However, this observation is complicated by the fact that the volume of a joint effusion does not correlate with its hydrostatic pressure $^{1113}$ as the complex mechanical behaviour of the articular structures has to be consideredfor example, capsular elasticity and viscoelasticity. In this study the mean age of patients with acute traumatic effusions was 28 years compared with 62 years for the group with chronic effusions, and it is known that joint elasticity increases with increasing age, ${ }^{29}$ suggesting a greater ability to generate high intra-articular pressures. Conversely, the size and strength of quadricep muscles decline with increasing age, ${ }^{30}$ suggesting a decreased ability for the generation of intra-articular pressure. Thus there are several factors that may influence the ability to generate high intra-articular pressures. In this study the effect of quadriceps inhibition in the patients with acute traumatic effusions appears to be the most fundamental and influential factor on their failure to generate high intra-articular pressures.

As the generation of increased intra-articular pressure is central to the mechanism of hypoxic- reperfusion injury, the failure to generate pathologically high intra-articular pressures in patients with acute traumatic effusions suggests that quadriceps inhibition, in this instance, may be a protective mechanism.

PM was supported as an Arthritis and Rheumatism Council (ARC) junior research fellow during these studies. DRB is an ARC professor of rheumatology. NC is an honorary lecturer at the London Hospital Medical College.

1 McCord J M. Oxygen-derived free radicals in post-ischaemic tissue injury. N Engl f Med 1985; 312: 159-63.

2 Allen R E, Blake D R, Nazhat N B, Jones P. Superoxide radical generation by inflamed human synovium after hypoxia. Lancet 1989; ii: 282-3.

3 Blake D R, Merry P, Unsworth J, et al. Hypoxic-reperfusion injury in the inflamed human joint. Lancet 1989; i: 289-93.

4 Merry P, Grootveld M, Blake D R. Hypoxic-reperfusion injury in the inflamed joint. Lancet 1989; i: 1023

5 Merry $P$. Hypoxic-reperfusion injury in the inflamed joint [MD Thesis]. London: University of London.

6 Merry P, Kidd B L, Blake D R. Synovitis of the joint is an example of reperfusion injury. In: Beaumont $\mathrm{P} C$, Deeble D J, Parsons B J, Rice-Evans C, eds. Free radicals, metal ions, and biopolymers. London: Richelieu Press, 1989: ions, and 215 .

7 Geborek P, Forslind K, Wollheim F A. Direct assessment of synovial blood flow and its relation to induced hydrostatic pressure changes. Ann Rheum Dis 1989; 49: 281-6.

8 Grootveld M, Henderson E B, Farrell A, Blake D R, Parkes H G, Haycock P. Oxidative damage to hyaluronate and $H$ G, Haycock $P$. Oxidative damage to hyaluronate and
glucose in synovial fluid during exercise of the inflamed glucose in synovial fluid during exercise of the inflamed joint: detection of abnormal low molecular weight meta-
bolites by proton nuclear magnetic resonance spectroscopy. bolites by proton nuclear magnetic

9 Merry P, Gray L, Lunec J, Blake D R. Exercise induces oxidative damage to synovial fluid albumin [abstract]. $\mathrm{Br} \mathcal{F}$ Rheumatol 1990; 29 (suppl 2): 25.

10 Hayes K C, Sullivan J. Tonic neck reflex influence on tendon and Hoffman reflexes in man. Electromyogr Clin Neurophysiol 1976; 16: 251-61.

11 Caughy D E, Bywaters E G L. Joint fluid pressure in chronic knee effusions. Ann Rheum Dis 1963; 22: 106-9.

12 Palmer D G, Myers D B. Some observations of joint effusions. Arthritis Rheum 1968; 11: 745-55.

13 Jayson M I V, Dixon A St J. Intra-articular pressure in rheumatoid arthritis of the knee. I. Pressure changes rheumatoid arthritis of the knee. I. Pressure changes during

14 Guyton A C, Taylor A E, Granger H J. Circulatory physiology: dynamics and control of the body fluids. Vol 2. Philadelphia: Saunders, 1975

15 Levick J R. Blood flow and mass transport in synovial joints In: Renkin E M, Michel C C, eds. Handbook of physiolog $I I$, cardiovascular system IV, the microcirculation. Bethesda: American Physiology Society, 1984: 914-47.

16 Zwei ach B W. Quantitative studies of microcirculatory structure and function. I. Analysis of pressure distribution in the terminal vascular bed in cat mesentery. Circ Res in the terminal vasc

17 Stokes M, Young A. The contribution of reflex inhibition to arthrogenous muscle weakness. Clin Sci 1984; 67: 7-14.

arthrogenous muscle weakness. Clin $S_{c i} 1984 ; 67: 7-14$.
18 Jones D W, Jones D A, Newham D J. Chronic knee effusion and aspiration: the effect on quadriceps inhibition. $\mathrm{Br} \mathcal{J}$ Rheumatol 1987; 26: 370-4.

19 Jayson M I V, Dixon A St J. Intra-articular pressure in rheumatoid arthritis of the knee. III Pressure changes during joint use. Ann Rheum Dis 1970; 29: 401

20 Unsworth J, Outhwaite J, Blake D R, Morris C J, Freeman J Lunec J. Dynamic studies of the relationship between intra-articular pressure, synovial fluid oxygen tension, and lipid peroxidation in the inflamed knee: an example of reperfusion injury. Ann Clin Biochem 1988; 24: 1-4.

21 Reeves B. Negative pressure in knee joints. Nature 1966; 212 : 1046.

22 Hallen L G, Lindahl O. Muscle function in knee extension an EMG Study. Acta Orthop Scand 1967; 38: 434-44.

23 Petersen I, Stener B. Experimental evaluation of the hypothesis of ligamento-muscular protective reflexes. III. A study in man using the medial collateral ligament of the knee joint. Acta Physiol Scand 1959; 48 (suppl 166): 51-61.

24 Basmajian J V. Re-education of vastus medialis: a misconception. Arch Phys Med 1970; 51: 245-7.

25 De Andrade J R, Grant C, Dixon A St J. Joint distension and reflex muscle inhibition in the knee. $\mathcal{F}$ Bone foint Surg [Am] 1965; 47: 313-22.

26 Ekholm J, Eklund G, Skogland S. On the reflex effects from the knee joint of the cat. Acta Physiol Scand 1960; 50 167-74.

27 Wood L, Ferrell W R. Response of slowly adapting articular mechanoreceptors in the cat knee joint to alterations in intra-articular volume. Ann Rheum Dis 1984; 43: 327-32.

28 Spencer J D, Hayes K C, Alexander I J. Knee joint effusions and quadriceps reflex inhibition in man. Arch Phys Med Rehabil 1984; 65: 171-7.

29 Myers D B, Palmer D G. Capsular compliance and pressurevolume relationship in normal and arthritic knees. $\mathcal{F}$ Bone volume relationship in normal and
foint $S$ urg $[\mathrm{Br}] \cdot 1972 ; 54: 710-6$.

30 Young A, Hughes I, Round J M, Edwards R H T. The effect of knee injury on the number of muscle fibres in the human quadriceps femoris. Clin Sci 1982; 62: 227-34. 